\title{
Clinico-Pathological Spectrum of Endometrial Lesions in Patients with Abnormal Uterine Bleeding in Accordance with PALM-COEIN Classification: A Prospective Study of 3 Years in a Tertiary Care Hospital of Western Uttar Pradesh
}

\author{
Roobina Khan ${ }^{1}$, Sadaf Haiyat ${ }^{1 *}$, Veena Maheshwari ${ }^{1}$ and Seema Hakim ${ }^{2}$ \\ 'Department of Pathology, JN Medical College, A.M.U, Uttar Pradesh, India \\ ${ }^{2}$ Department of Obstetrics and Gynecology, JN Medical College, A.M.U, Uttar Pradesh, India
}

\begin{abstract}
Background: Abnormal uterine bleeding (AUB) is one of the most frequently encountered gynecological complaints in women associated with considerable morbidity and mortality. This study may help clinicians in our population to improve their therapeutic strategies by resorting to minimally invasive modalities and avoiding unnecessary hysterectomies. The aim of this study is to study the clinic-pathological spectrum and histological patterns various endometrial lesions in patients with AUB in accordance with PALM-COEIN classification.

Methods: The present study was carried out on 265 patients over a period of 2 years in the Department of Pathology, Jawaharlal Nehru Medical College, A.M.U, Aligarh. Endometrial tissue was collected by dilatation and curettage (D and C) and endometrial biopsy and was sent to the histopathology laboratory for evaluation.

Result: The most common clinical presentation was menorrhagia (43.4\%), followed by metrorrhagia (19.3\%). Age of patients ranged from 15 to 70 years with peak incidence found in the 5 th decade (41-50 years) (35.4\%). On histopathological examination, non- structural causes accounted for the majority of the diagnosis (37\%) in which normal cyclical endometrium (AUB-E) was the commonest lesion seen in $37.8 \%$ of cases. Endometrial hyperplasia (AUB-M) was the most common histopathological diagnosis $84(31.7 \%)$ amongst structural causes in our study. This was followed by endometrial polyp (AUB-P) in $12(4.5 \%)$ cases and endometrial carcinoma in $4(1.5 \%)$ respectively.

Conclusion: Our study revealed a clustering of cases around peri-menopausal age group. Histopathological examination of endometrium is gold standard diagnostic tool in evaluation of AUB and there is an age specific association of endometrial lesions.
\end{abstract}

\section{Keywords: : Abnormal uterine bleeding, Dilatation and Curettage, PALM-COEIN, Histopathology}

\section{Introduction}

Endometrial diseases are ranked amongst the most common gynaecological disorders, affecting women worldwide. [1] These constitute around $70 \%$ of all gynaecologic consultations in the peri-menopausal and postmenopausal age group. A large number of females with endometrial diseases present with abnormal uterine bleeding (AUB), hence it warrants an urgent diagnosis. Abnormal uterine bleeding affects nearly $9-14 \%$ of women between menarche and menopause, significantly impacting their quality of life and imposing a financial burden. ${ }^{[2]}$ It is one of the most challenging problems encountered by the gynecologists regardless of the age of the women. ${ }^{[3]} \mathrm{AUB}$ affects around $10-30 \%$ of reproductive-aged female and up to $50 \%$ of peri-menopausal woman. ${ }^{[2]}$

Abnormal Uterine Bleeding (AUB) is defined as any excessive or erratic bleeding that does not correspond with the frequency, duration or amount of blood flow of a normal menstrual cycle. ${ }^{[2,4]}$ and could be a sign of simple hormonal imbalance or a serious underlying condition necessitating aggressive treatment including a major surgical procedure. There is a wide spectrum of morphological patterns of endometrium in patients of AUB ranging from simple hormonal imbalance to endometrial hyperplasia and carcinoma. The PALMCOEIN classification system has been recently approved as a FIGO system for the etiological classification of AUB in 2011, where PALM stands for (polyp, adenomyosis, leiomyoma, malignancy, and hyperplasia) comprising structural causes and COEIN for (coagulopathy, ovulatory dysfunction, endometrial, iatrogenic and not yet classified) denoting non-structural causes. This classification system was developed with the aim that it could be used by clinicians, investigators, and even patients to facilitate communication, clinical care, and research. ${ }^{[5]}$ Majority of these lesions are diagnosed by sampling the endometrium. There are several methods 
for endometrial sampling like endometrial biopsy, hysteroscopy and dilatation and curettage (D\&C), amongst which $\mathrm{D} \& \mathrm{C}$ is considered to be a method of choice. ${ }^{[6]}$ Dilatation and curettage is a useful and cost-effective method of detecting intrauterine pathologies and very few lesions escape detection. ${ }^{[7]}$ It serves as a standard tool for assessing patients of abnormal uterine bleeding mostly in developing countries with limited resources.

Many women with abnormal uterine bleeding may undergo unwarranted hysterectomy without a definite diagnosis. ${ }^{[8]}$ In women above 40 years and certainly in menopausal patients, it mandates evaluation to confirm benign nature of the problem, so that medical treatment or conservative surgery can be offered and unnecessary radical surgery can be avoided. ${ }^{[9]}$

The objectives of our study are to evaluate the clinicopathological profile of patients, determine the frequencies of endometrial lesions in endometrial biopsy and curettage presenting with abnormal uterine bleeding and to stratify the various causes of abnormal uterine bleeding in accordance with the latest PALM-COEIN classification

\section{Materials and Methods}

The present study was conducted in the Department of Pathology, Jawaharlal Nehru medical college, AMU, a tertiary care hospital in Aligarh, Western Uttar Pradesh over a period of 2 years from November 2013 to November 2015 with the approval of ethics committee. A total of 265 patients presenting with abnormal uterine bleeding were included in the study. All patients with pregnancy -related complications like abortions, gestational trophoblastic disease or ectopic pregnancy, cervical pathologies, systemic causes and bleeding diathesis were excluded from our study. The clinical data were obtained from the gynaecology case files, laboratory request forms and patients record wherever available. Endometrial specimens were received from the gynaecological ward and outpatient clinics in the form of endometrial biopsy and curettage.

All the specimens were processed in Histokinette automated tissue-processor. Paraffin blocks were prepared and tissue sections of 3-5micron were cut. The sections were stained with haematoxylin and eosin stains (H\&E) and examined microscopically by the pathologist.

The data were analysed and percentages for each category were calculated.

\section{Results}

A total of 265 women with complaints of abnormal uterine bleeding were included in our study. The majority of the women were in the $5^{\text {th }}$ decade $(35.4 \%)$ followed by $4^{\text {th }}$ decade $(30.6 \%)$ and $10.6 \%$ patients were encountered in the post-menopausal age group ( $>50$ years). [Table1] An increase in the incidence of AUB with parity was noticed in our study. An overwhelming majority (40.80\%) of women were grandmultipara however, $(6.4 \%)$ cases were found to be nulliparous. [Table 2] Most of the study population lived in the urban area $(69.7 \%)$ and around $58.01 \%$ belonged to poorer sections of society, i.e. class III or less of modified Prasad classification.

The most common presenting complaint among our patients was menorrhagia $115(43.4 \%)$, followed by metrorrhagia $51(19.3 \%)$ and oligomenorrhoea 33(12.4\%). The least common complaint was polymenorrhagia found only in 10 cases $(3.8 \%)$, as illustrated in Fig1. An age-specific comparative analysis of the clinical presentation revealed that menorrhagia was the commonest complaint in the 4150 years and 31-40 years' age group accounting for (44.4\%) and $(40.9 \%)$ respectively, however, oligomenorrhoea was most commonly seen in the age group of 21-30 years and post-menopausal bleeding accounted for the majority of complaints in post-menopausal age group.

Fig 2 shows the distribution of cases on histopathology according to PALM-COEIN classification, wherein nonstructural causes (COEIN) accounted for the majority of the cases $(63 \%)$ in our study followed by structural causes in $(37 \%)$ cases respectively. Amongst non-structural causes (63\%), normal cyclical endometrium (AUB-E) accounted for a majority of the diagnosis (37.8\%), in which proliferative endometrium was the most common pattern $(28.7 \%)$ followed by secretory endometrium accounting for $9.1 \%$ cases respectively. This was followed by chronic endometritis (AUB-E) in 26(9.8\%) cases in which 2 cases $(0.7 \%)$ demonstrated caseating granulomas and Langhans giant cells, the hallmark features of granulomatous endometritis and rest 24(9.0\%) were diagnosed as chronic non-specific endometritis. Other endometrial lesions included luteal phase insufficiency (AUB-O) in $14(5.3 \%$ ) cases, disordered proliferative endometrium (AUB-E) in $11(4.2 \%)$ cases, and pill effect (AUB-I) in 6(2.3\%) cases respectively. Atrophic endometrium (AUB-E) was the least common 5(1.8\%) histopathological lesion encountered. Endometrial hyperplasia (AUB-M) was the major contributor (31.7\%) amongst the category of structural causes $(37 \%)$, followed by endometrial polyp (AUB-P) in (4.5\%) cases and endometrial carcinoma (AUB-M) in $(1.5 \%)$ respectively. [Table 3] On categorization of endometrial hyperplasia, the majority of the cases were diagnosed as simple hyperplasia without atypia $(\mathrm{SH})$ in $(67.8 \%)$ cases, followed by $21(25 \%)$ cases of complex hyperplasia without atypia $(\mathrm{CH})$. Complex atypical hyperplasia $(\mathrm{CAH})$ accounted 
for $(4.8 \%)$ cases and simple atypical hyperplasia (SAH) $(2.4 \%)$ respectively.

An age-specific association of endometrial lesions in patients of AUB was also observed in our study. Table 4 shows the distribution of histological pattern of endometrium in patients with AUB uterine bleeding according to their age groups, amongst the reproductive age group (15-40 years) normal cyclical endometrium was predominantly seen. This included proliferative endometrium seen in $60(78.9 \%)$ and secretory endometrium in 18 (75\%). A significant number of patients with simple hyperplasia without atypia (36.8\%) were also observed in this age group. Most of the patients with luteal phase insufficiency (64.3\%), endometritis (53.8\%), pill effect (50\%) and DPE(45.5\%) were also commonly seen in this age group. No atypical hyperplasia or malignancy was found in this age group.
Endometrial hyperplasia was the commonest contributor among perimenopausal women (41-50 years). This included simple hyperplasia without atypia in $30(52.6 \%)$ followed by complex hyperplasia without atypia in $10(47.6 \%)$. The majority of the cases of endometrial polyp (50\%) and DPE (45.5\%) were also commonly seen amongst perimenopausal women. Endometritis was commonly seen (38.5\%) amongst the functional causes in this age group. Atypical hyperplasia was seen only in 2 cases $(2.1 \%)$ and a single case of malignancy was also found in this age group. In postmenopausal women, the most frequently encountered lesion was atrophic endometrium (80\%). This was followed by malignancies (75\%) and atypical hyperplasia (66.7\%) cases. all were diagnosed as invasive endometrial carcinoma. Finally, in $3(1.1 \%)$ cases, the endometrial curetting's were scanty and inadequate for any opinion.

Table1: Distribution of Cases According to Age Group.

\begin{tabular}{|c|c|c|}
\hline AGE GROUP (in years) & NO.OF CASES & PERCENTAGE (\%) \\
\hline$\leq 20$ & 5 & 21.5 \\
\hline $21-30$ & 57 & 30.6 \\
\hline $31-40$ & 81 & 35.4 \\
\hline $41-50$ & 94 & 9.1 \\
\hline $51-60$ & 24 & 1.5 \\
\hline$>60$ & 4 & 100 \\
\hline TOTAL & 265 & 1.9 \\
\hline
\end{tabular}

Table 2: Distribution of Cases According to Parity.

\begin{tabular}{|c|c|c|}
\hline PARITY & NO. OF CASES & PERCENTAGE (\%) \\
\hline NULLIPARITY & 17 & 18.4 \\
\hline LOW PARITY(P1-P2) & 48 & 36.6 \\
\hline MULTIPARITY(P3-P4) & 97 & 38.9 \\
\hline GRANDMULTIPARITY( $\geq$ P5) & 103 & $\mathbf{1 0 0} \%$ \\
\hline
\end{tabular}

Table 3: Histopathological Distribution of Cases According to (Palm-Coein) Classification.

\begin{tabular}{|l|l|l|l|}
\hline ENDOMETRIAL HISTOPATHOLOGY & $\begin{array}{l}\text { FIGO classification } \\
\text { (PALM-COEIN) }\end{array}$ & NO. OF PATIENTS & Percentage (\%) \\
\hline NON-STRUCTURAL CAUSES & AUB-E & 76 & 28.7 \\
\hline Proliferative & AUB-E & 24 & 9.1 \\
\hline Secretory & AUB-O & 14 & 5.3 \\
\hline Luteal phase insufficiency & AUB-E & 11 & 4.2 \\
\hline Disordered proliferative endometrium & AUB-I & 6 & 2.3 \\
\hline Exogenous hormones/pill effect & AUB-E & 26 & 9.8 \\
\hline Endometritis & AUB-E & 5 & 1.8 \\
\hline Atrophic endometrium & & & \\
\hline
\end{tabular}




\begin{tabular}{|l|l|l|l|}
\hline ENDOMETRIAL HISTOPATHOLOGY & $\begin{array}{l}\text { FIGO classification } \\
\text { (PALM-COEIN) }\end{array}$ & NO. OF PATIENTS & Percentage (\%) \\
\hline STRUCTURAL CAUSES & AUB-P & 12 & 4.5 \\
\hline Endometrial polyp & AUB-M & 84 & 31.7 \\
\hline Endometrial hyperplasia & AUB-M & 4 & 1.5 \\
\hline Endometrial cancer & - & 3 & 1.1 \\
\hline Inadequate & & $\mathbf{2 6 5}$ & $\mathbf{1 0 0}$ \\
\hline Total & & & \\
\hline
\end{tabular}

Footnote: AUB- Abnormal uterine bleeding, AUB-E: Endometrial cause (Inflammation ,infection) , AUB-O: Ovulatory dysfunction, AUB-I: Iatrogenic, AUB-P: Polyp, AUB-M: Hyperplasia and Malignancy

Table 4 : Distibution of Histopathological Lesions According to Age Groups

\begin{tabular}{|l|c|c|c|c|}
\hline HISTOPATHOLOGICAL DIAGNOSIS & $\begin{array}{c}\text { REPRODUCTIVE } \\
(\mathbf{1 5 - 4 0} \text { years) }\end{array}$ & $\begin{array}{c}\text { PERIMENOPAUSAL } \\
(\mathbf{4 1 - 5 0} \text { years) }\end{array}$ & $\begin{array}{c}\text { POSTMENOPAUSAL } \\
(>\mathbf{5 0} \text { years) }\end{array}$ & $\begin{array}{c}\text { TOTAL } \\
(\%)\end{array}$ \\
\hline Proliferative endometrium(AUB-E) & $60(78.9 \%)$ & $15(19.7 \%)$ & $1(1.4 \%)$ & $76(100 \%)$ \\
\hline Secretory endometrium(AUB-E) & $18(75 \%)$ & $6(25.0 \%)$ & - & $24(100 \%)$ \\
\hline Luteal phase insufficiency(AUB-O) & $9(64.3)$ & $5(35.7 \%)$ & - & $14(100 \%)$ \\
\hline Disordered proliferative endometrium (AUB-E) & $5(45.5 \%)$ & $5(45.5 \%)$ & $1(9.0 \%)$ & $11(100 \%)$ \\
\hline Exogenous hormones/Pill effect(AUB-I) & $3(50 \%)$ & $2(33.3 \%)$ & $1(16.7 \%)$ & $6(100 \%)$ \\
\hline Atrophic endometrium(AUB-E) & - & $1(20 \%)$ & $4(80 \%)$ & $5(100 \%)$ \\
\hline Endometritis(AUB-E) & $14(53.8 \%)$ & $10(38.5 \%)$ & $2(7.7 \%)$ & $26(100 \%)$ \\
\hline Endometrial polyp (AUB-P) & $3(25 \%)$ & $6(50.0 \%)$ & $3(25 \%)$ & $12(100 \%)$ \\
\hline Simple hyperplasia without atypia(AUB-M) & $21(36.8 \%)$ & $30(52.6 \%)$ & $6(10.6 \%)$ & $57(100 \%)$ \\
\hline Complex hyperplasia without atypia (AUB-M) & $8(38.1 \%)$ & $10(47.6 \%)$ & $3(14.3 \%)$ & $21(100 \%)$ \\
\hline Atypical hyperplasia(AUB-M) & & $2(33.3 \%)$ & $4(66.7 \%)$ & $6(100 \%)$ \\
\hline Endometrial carcinoma(AUB-M) & - & $1(25 \%)$ & $3(75 \%)$ & $4(100 \%)$ \\
\hline
\end{tabular}

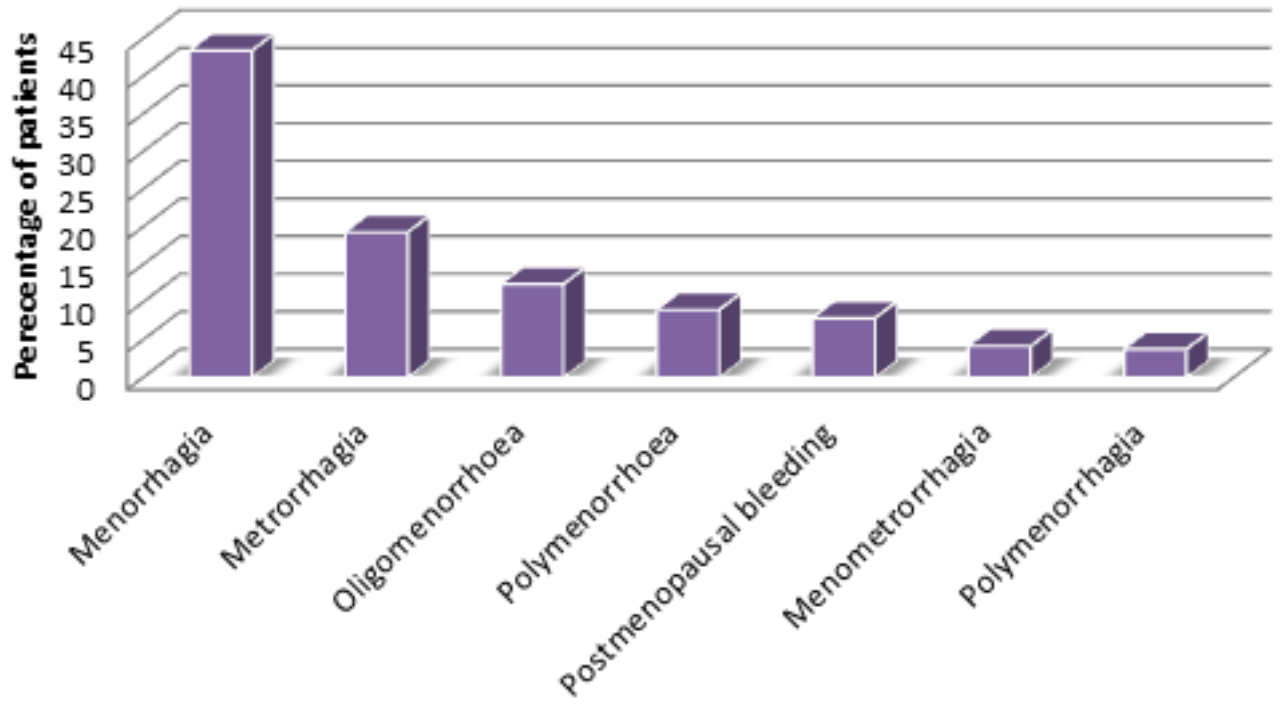

Fig. 1: Distribution of Cases Acccording to Clinical Presentation. 


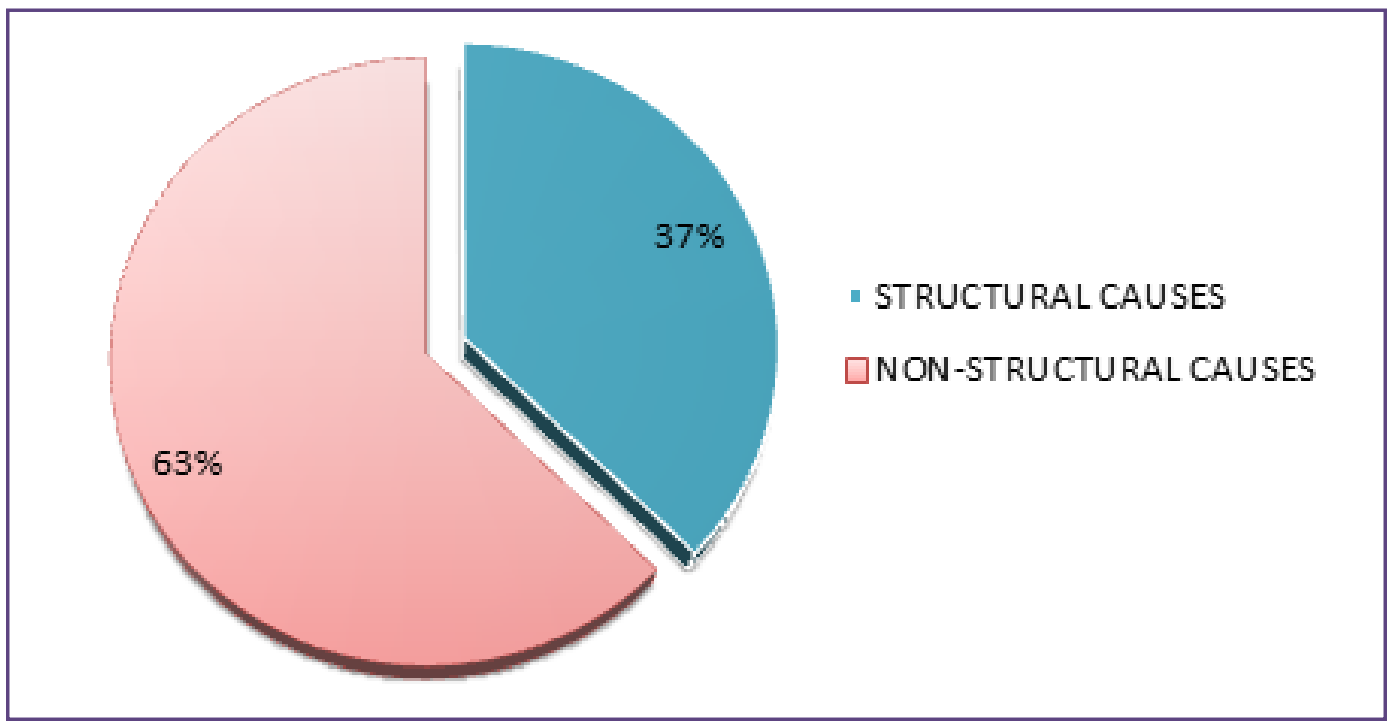

Fig. 2: PALM-COEIN classification of AUB.

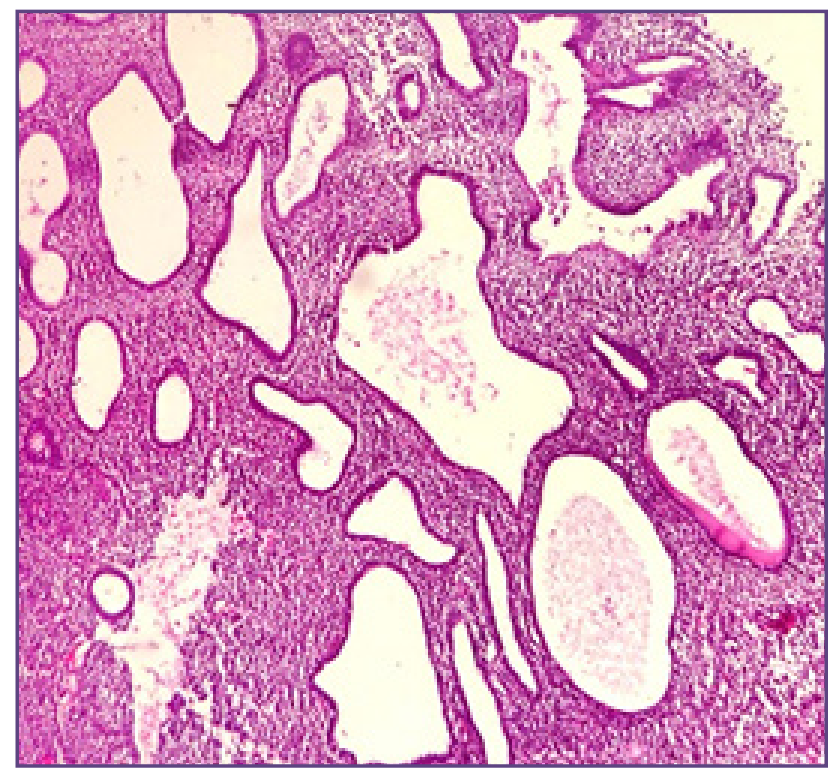

Fig. 3: Simple hyperplasia without atypia showing variable sized cystically dilated glands lined by low columnar epithelium in a cellular stroma.(H\&E, 10X).

\section{Discussion}

Abnormal uterine bleeding is one of the most frequently encountered complaints in gynaecological practice posing a considerable health risk. AUB is excessive, erratic, or irregular bleeding usually associated with hormonal disturbance or intrauterine pathology. It accounts for more than two-thirds of all gynaecological consultations in the peri and postmenopausal years. ${ }^{[10]}$ Endometrial assessment is performed to diagnose malignancy or pre-malignant conditions and to evaluate the hormonal influences of the endometrium.

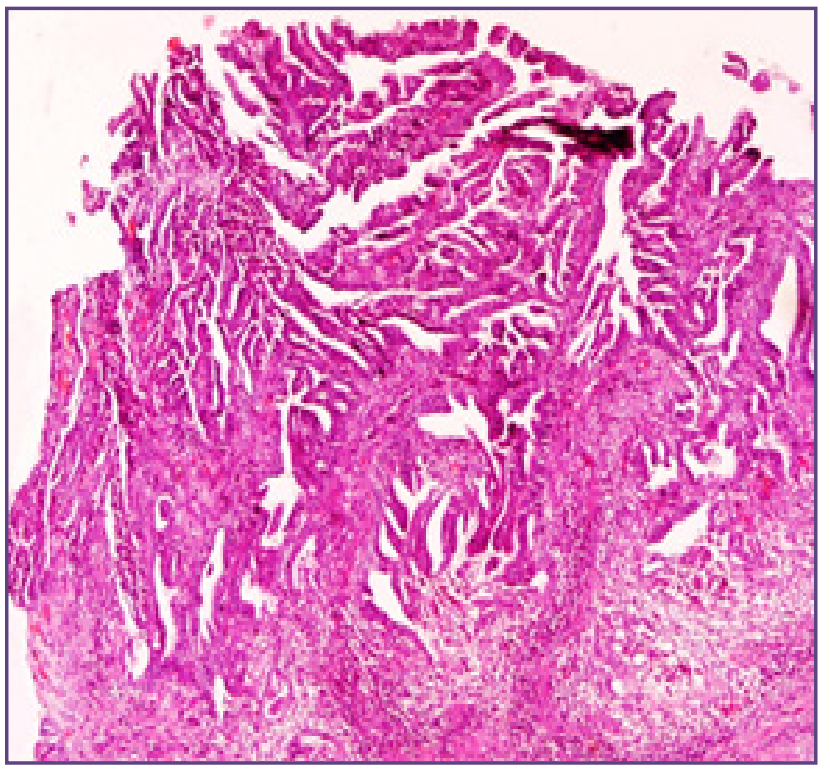

Fig. 4: Well differentiated adenocarcinoma showing closely packed, irregularly shaped glands invading into the stroma. (H\&E, 10X).

A total of 265 endometrial samples of patients with abnormal uterine bleeding were assessed. Our study had a maximum number of patients in the $5^{\text {th }}$ decade $(35.4 \%)$ and $4^{\text {th }}$ decade $(30.6 \%)$ followed by $3^{\text {rd }}$ decade $(21.5 \%)$. These findings were in concordance with the study of Abdullah and Bondagji and Saraswathi D et al who had reported a similar incidence of $32.1 \%$ and $33.5 \%$ in $5^{\text {th }}$ decade respectively. ${ }^{[11,12]}$ An increased number of cases in this age group could be due to the fact that as menopause approaches, there is a reduction in the number of ovarian follicles and their increased resistance to gonadotrophic 
stimulation, resulting in a low level of estrogen, which cannot keep the normal endometrium growing. The lesser number of patients was seen in the post-menopausal, which could be due to earlier evaluation, detection as well as management of the disease.

The incidence of AUB in our study showed an increasing trend with an increase in parity. Majority of the females were grandmultipara (38.9\%) and multipara (36.6\%), however primiparous and nulliparous constituted $18.1 \%$ and $6.4 \%$ respectively. These findings were consistent with the results reported by Mahmoud et al. ${ }^{[13]}$ Abnormal uterine bleeding usually presents with variable bleeding patterns. Our study showed menorrhagia as the commonest complaint (43.4\%) followed by metrorrhagia 51 (19.3\%). These results closely corroborated by the figures quoted by Sujata et al and Zeeba et al respectively. ${ }^{[14,15]}$

The PALM-COEIN classification has an advantage of consideration of the entire plethora of aetiologies of AUB. According to PALM-COEIN, our study showed the maximum incidence of non- structural causes/functional causes $161(63.0 \%)$ as compared to structural/organic cause $104(37.0 \%)$ in patients of AUB. This was comparable with the findings of Mahmoud and Rifat who reported functional (61.3\%) and organic (38.7\%). ${ }^{[13]}$ Similar results were also observed by Mirza et al where functional causes constituted (57\%) and organic causes(43\%) respectively. ${ }^{[15]}$ The most common pattern amongst the non-structural causes was normal cyclical endometrium (AUB-E ) which included proliferative $(28.7 \%)$ and secretory $(9.1 \%)$, the total amounting to $36.8 \%$. This is similar to a study done by Abdullah LS et al. ${ }^{[16]}$ The incidence of proliferative endometrium compares favourably with that of $33 \%$ by Riaz S et al, however, a slightly lower incidence of $21.74 \%$ by Saraswathi D et al and $24 \%$ by Jairajpuri ZS et al has also been reported. ${ }^{[12,17,18]}$ This may be due to the selection criteria and timing of D \& C. The bleeding in this group is most likely due to the hormonal imbalance leading to intermittent anovulatory cycles which leads to progressive rise of estrogen to comparatively high levels, followed by a sudden fall in estrogen due to feedback inhibition by pituitary resulting in bleeding.

Disordered proliferative endometrium (AUB-E) was seen in 11 cases $(4.2 \%)$ in our study which was similar to $6.8 \%$ by Jetley et al. ${ }^{[19]}$ Disordered proliferative endometrium is an exaggeration of the normal proliferative phase, consisting of glands lined by cytologically bland, pseudostratified, mitotically active epithelium, having a normal ratio of glands to stroma and is due to persistent oestrogen stimulation. ${ }^{[20,21]}$ This pattern was particularly seen in perimenopausal women in our study $(45.5 \%)$. This was similar to $57.8 \%$ incidence of DPE in perimenopausal women by Sajitha et al. ${ }^{[22]}$ The diagnosis of this entity at the earliest stage of the spectrum will be of definitive help to the practicing gynaecologists to prevent the disease progression.

The incidence of endometritis observed in our study was $26(9.8 \%)$. This was concordant with the reported incidence of $9.4 \%$ by Usha GD et al and $7.7 \%$ by Wahda et al. ${ }^{[23,24]}$ However various other studies had observed variation with a higher incidence of $13 \%$ and 375 reported by Muzaffar et al and Parveen et al respectively. ${ }^{[25,26]}$ The variation may be due to socioeconomic status, hygienic conditions or exposure to the surgical intervention. The histopathologic diagnosis of chronic endometritis is characterized by the presence of plasma cells in the endometrial stroma with or without accompanying acute inflammation and lymphocytes. ${ }^{[27]}$ Out of the 26 cases of CE, the majority of them $(20 / 26,7.5 \%)$ were of chronic non-specific endometritis followed by 2 cases of specific endometritis particularly granulomatous endometritis in our study. Similarly, Jetley et al had reported 2 cases of granulomatous endometritis out of 20 in their study. ${ }^{[19]}$

Our study showed evidence of pill effect in 6 cases $(2.3 \%)$ which was in agreement with an incidence of $2.3 \%$ reported by Jetley et al. ${ }^{[19]}$ The histology shows a combination of inactive glands, abortive secretions, and thin blood vessels. ${ }^{[27]}$ This pattern was predominantly seen in the reproductive age group (50\%). This was probably due to an increased number of patients resorting to early medical management for bleeding. However, Sajitha et al reported maximum incidence in peri-menopausal women. ${ }^{[22]}$ We observed atrophic endometrium in 5 cases $(1.8 \%)$, and all of them belonged to the postmenopausal age group. This was comparable to $1 \%$ by Khan $\mathrm{S}$ et al and $1.1 \%$ by Jairajpuri ZS et al. ${ }^{[28,17]}$ However the reproductive and peri-menopausal age group showed no such pattern.

Amongst structural causes, endometrial hyperplasia was the commonest lesion noted in 84 cases $(31.7 \%)$, out of those $(78 / 84=92.9 \%)$ showed hyperplasia without atypia and $(6 / 84=7.1 \%)$ with atypia. Endometrial hyperplasia is the precursor of carcinoma and usually presents with abnormal uterine bleeding. It was seen most frequently in peri-menopausal age group $(46 \%)$ followed the reproductive age group (15.5\%) respectively. The reason could be due to anovulation leading to persistent unripened follicles exposing the endometrium to an abnormally and excessive prolonged estrogenic secretion. The figures are high in our studies because of the increased number of patients resorting in this age group for a health checkup. The majority of the patients constituted simple hyperplasia 
(SH) without atypia $(57 / 84,67.8 \%)$ in perimenopausal women. Similar studies performed by other researchers had reported that simple hyperplasia constituted $64.4 \%$ and $66.6 \%$ of all endometrial hyperplasia with the vast majority occurring in perimenopausal women. Some studies have observed sight variation like a lower percentage of $25 \%$ was reported by Riaz $\mathrm{S}$ et al and a higher figure of

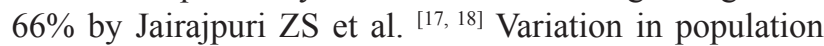
characteristics and use of hormonal therapy may also be the contributory factors to these differences.

Overall, complex hyperplasia without atypia was observed in $(21 / 265=7.9 \%)$ in our study. The incidence was quite higher compared to $2.8 \%$ by Khan $\mathrm{S}$ et al. ${ }^{[28]}$ Amongst hyperplasia $\mathrm{CH}$ was seen in $(21 / 84,25 \%)$ which was similar to $28.7 \%$ reported by Mahmoud and Rifat 2013. [10] However simple atypical hyperplasia (SAH) and complex atypical hyperplasia(CAH) constituted $2.4 \%$ and $4.8 \%$ respectively. A similar incidence of SAH (3.85\%) and CAH (7.05\%) was reported by Sajitha et al. ${ }^{[22]}$

Our study showed 12 cases (4.5\%) of endometrial polyps. This was comparable to $4.2 \%$ by Sarwat Ara et al and 3\% by Forae and Aligbe. ${ }^{[2,30]}$ However a lower incidence of $1.7 \%$ and $1.2 \%$ had been reported by Jairajpuri ZS et al and a relatively high incidence of $12 \%$ and was observed by Mirza et al. ${ }^{[15,18]}$ The reason for this variation in the studies are not known but may be linked to geoethnical variation. Majority of the polyps $50 \%$ were seen in perimenopausal age group. This was in concordance with $54.5 \%$ by Jairajpuri ZS et al and $39.1 \%$ by Saraswathi D

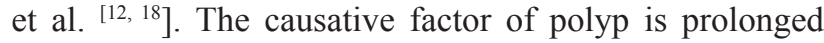
estrogen stimulation, which leads to hyperplasia of the basal endometrial layer. A relatively lower incidence of the polyp was seen in the reproductive age group in our study which could be attributed to a possible spontaneous regression mechanism, which is characteristic of the cyclic endometrium in reproductive age group Saraswathi D et al. ${ }^{[12]}$

Endometrial carcinoma was the least common pathology in our study found in $4(1.5 \%)$ in our study. Similar results were reported as $1.0 \%$ by Riaz S et al and $1.8 \%$ by Abdullah LS et al ${ }^{[16,17]}$ Our study showed a lower incidence as compared to $4.4 \%$ by Saraswathi D et al. ${ }^{[12]}$ This may be attributed to the practice of early childbearing and multiparity in our society. It was seen most commonly in postmenopausal age group (75\%) followed by perimenopausal (25\%).Our study also showed 3 cases $(1.1 \%)$ as unsatisfactory for an opinion. Most of these showed large areas of hemorrhage and scanty glands or stroma. These cases were labeled inconclusive for any opinion and the clinician was advised to repeat biopsy if clinically indicated. This situation exemplifies that the biopsy/curettage should be done at an appropriate time so as to be able to salvage a much of tissue as possible for the diagnosis.

Endometrial cause of AUB is an age-related pathology. Histopathological examination of endometrial biopsy is a major diagnostic tool in the evaluation of AUB and a specific diagnosis could help the physician to plan therapy for successful management of AUB. Due to its descriptive nature, our study may not be complete in all aspects. However, this study would provide a database with regard to the histopathological spectrums in abnormal uterine bleeding in our population. This database may help gynaecologist to modify their treatment strategies. Furthermore, based on common endometrial pathologies in our population, health literacy, screening programme etc., can be constructed effectively.

\section{Conclusion}

A wide spectrum of histopathological patterns of the endometrium was observed in our study. This ranged from simple physiological causes to much more complex pathological lesions. The vast majority of the lesions causing AUB encountered in this study were normal cyclical endometrium seen most commonly in reproductive women. However, endometrial hyperplasia was commonly seen in the perimenopausal age group and few cases of endometrial carcinoma were seen in postmenopausal women, thereby highlighting the importance of endometrial curetting and biopsy as a diagnostic procedure in the evaluation. The PALM COEIN classification system helps us in understanding various etiological causes of AUB and can be used by clinicians and researchers for international comparisons.

\section{Competing Interests}

The authors declare that there is no conflict of interest.

\section{Reference}

1. Sarwar A, Haque A. Types and frequencies of pathologies in endometrial curretings of abnormal uterine bleeding. Int J Pathol 2005; 3:6570.

2. Mary GS, Tarin AS and Patrice MW. Evaluation and management of abnormal uterine bleeding in premenopausal women.Am Fam Physician.2012; 85(1):35-43

3. Ozdemir S, Celik C and Gezginc $\mathrm{K}$ et al. Evaluation of endometrial thickness with transvaginal ultrasonography \& histopathology in premenopausal women with abnormal vaginal bleeding. Arch Gynecol Obstet 2010; 282(4):395399 .

4. Fraser IS, Langham S and Uhl-Hochgraeber K. Health-related quality of life and economic burden of abnormal uterine bleeding. Expert Rev Obstet. Gynecol.2009;4(2):179-189 
5. Munro MG, Critchley HO, Broder MS, Fraser IS. FIGO classification system (PALMCOEIN) for causes of abnormal uterine bleeding in nongravid women of reproductive age. Int J Gynaecol Obstet 2011;113:313

6. Baral R, Pudasaini S. Histopathological pattern of endometrial samples in abnormal uterine bleeding. Journal of Pathology of Nepal. 2011; 1:13-16.

7. Sher Z. Conventional dilatation and curettage; still a useful procedure. J Rawal Med Coll 2003; 19(4):27-30.

8. Chullapram T, Song JY, Fraser IS. Medium-term follow-up of women with menorrhagia treated by rollerball endometrial ablation. Obstet Gynecol 1996; 88: 71-76.

9. Goldenstein SR. Modern evaluation of endometrium. Obstet Gynecol 2010; 116: 168-176.

10. Mahmoud M. M, Aseel G. R, Endometrial Histopathological changes in women with Abnormal Uterine bleeding in Kirkuk City, a Clinicopathological Study. Med J of Babylon 2013; Vol 10, 567-582.

11. Abdullah LS, Bondagji NS. Histopathological pattern of endometrial sampling performed for abnormal uterine bleeding. Bahrain Med Bull.2011; 33:195200.

12. Saraswathi D, Thanka J, Shalinee R, Aarthi R, Jaya V, Kumar PV. Study of endometrial pathology in abnormal uterine bleeding. Obstet Gynaecol India.2011; 61:424430.

13. Mahmoud M. M, Aseel G. R, Endometrial Histopathological changes in women with Abnormal Uterine bleeding in Kirkuk City, A Clinicopathological Study. Med J of Babylon 2013; Vol 10, 567-582.

14. Zeeba S.J, S. R and S. J. Atypical uterine bleedingHistopathological audit of endometrium A study of 638 cases. Al Ameen J Med Sc i 2013; 6(1):21-28.

15. Mirza T, akram S and Mirza A et al.Histopathological pattern of abnormal uterine bleeding in endometrial biopsies 2012; 8:114-117.

16. Abdullah LS, Bondagji NS. Histopathological pattern of endometrial sampling performed for abnormal uterine bleeding. Bahrain Med Bull 2011; 33(4):1-6.

17. Riaz S, Ibrar F, Dawood NS, Jabeen A. Endometrial pathology by endometrial curettage in menorrhagia in premenopausal age group. J Ayub Med Coll Abbottabad 2010; 22(3):161-164.
18. Jairajpuri ZS, Rana S, Jetley S. Atypical uterine bleedingHistopathological audit of endometrium. A study of 638 cases. Al Ameen J Med Sci 2013; 6(1):21-28.

19. Jetley S, Rana S, Jairajpuri ZS; Morphological spectrum of endometrial pathology in middle aged women atypical uterine bleeding. J of Midlife, 2013; 4(4): 216-220.

20. Mazur MT, Kurman RJ. Normal endometrium and infertility evaluation. In: Mazur MT, Kurman RJ, editors. Diagnosis of endometrial biopsies and curettings: A practical approach. 2nd Ed. New York, NY:Springer- Verlag; 2005:7-33. Menopause 2009;16(1):50-69.

21. Mutter GL. Diagnosis of premalignant endometrial disease. J Clin Pathol 2002; 55:326-331.

22. Sajitha K, Shetty K, Hegde P, KishanPrasad H, Padma S, Permi H. Study of histopathological patterns of endometrium in abnormal uterine bleeding. CHRISMED Journal of Health and Research. 2014;1(2):76-81.

23. Usha GD, Doddamini G.B, Katageri G, Mallapur A.Clinicopathological Correlation of Endometrium in Abnormal Uterine Bleeding Sch. J. App. Med. Sci 2014; 2(1A):46-49

24. Wahda MT, Manal TA, and Safwan I. Histopathological Interpretation of Abnormal Uterine Bleeding after the Age of 40 year. The Iraqi Postgraduate Medical Journal 2010; 9:274-282.

25. Muzzafar M, Akhtar KAK, Yasmin S ,Rehman M, Iqbal W, Khan MA. Menstrual Irregularities with excessive blood loss: a clinico-pathological correlation. J Pak Med Assoc 2005; 55:486-489.

26. Parveen SH. Endometrium histology in abnormal uterine bleeding .Quarterly Medical Channel 2011; 17 (4):68-70.

27. Deligdisch L. Hormonal Pathology of the Endometrium. Modern Pathology, 2000; 13(3):285-294.

28. Khan S, Hameed S, Umber A. Histopathological pattern of endometrium on diagnostic D\& $\mathrm{C}$ in patients with abnormal uterine bleeding. Annals 2011; 17(2):166-170.

29. Sarwat Ara,Roohi M. Abnormal uterine bleeding; Histopathological diagnosis by conventional dilatation and curettage. Professional Med J 2011; 18(4): 587-591.

30. Forae GD, Aligbe JU. Histopathological patterns of endometrial lesions in patients with abnormal uterine bleeding in a cosmopolitan Population. J Basic clin Reprod Sci., 2013; 2(2): 101-104.

*Corresponding author:

Dr Sadaf Haiyat, Senior Resident, Department of Pathology, Jawaharlal Nehru Medical College and Hospital, A.M.U, Aligarh (Uttar Pradesh) 202002 INDIA Phone: +91 -8439762123

Email: sadafhayat143@gmail.com

Financial or other Competing Interests: None. 